\title{
Unemployed Graduates' Mental Health and the Place of Entrepreneurship Education in Achieving Nigeria's Vision 20:2020
}

\author{
${ }^{1}$ M. B. I. Omoniyi and ${ }^{2}$ E.O. Osakinle \\ ${ }^{1}$ Adekunle Ajasin University, ${ }^{2}$ University of Ado Ekiti, Nigeria
}

\begin{abstract}
The total number of approved universities in Nigeria has since risen to 97 made up of 27 Federal, 32 State Government and 38 privately-owned universities and more licences are being granted. These universities are churning out graduates in their thousands, graduates who are sound in the theories of their disciplines but poor in the practice. Majority of the graduates find it difficult to get employment every year. The focus of this study was to examine the psychological impact of unemployment on the mental health of Nigeria graduates and the place of entrepreneurship education as a panacea.

Five research hypotheses were raised to guide the study. A self constructed 25 items questionnaire was employed to elicit information from the 167 subjects for the study. The face and content validities of the instrument were ensured while it's reliability was ascertained through a test-re-test method with a reliability coefficient of 0.75 . The data collected were subjected to appropriate descriptive (means and standard deviation) and inferential (t-test) statistics. The results revealed that: the perceived level of stress among both male and female unemployed graduates is not significantly different. The result further indicated that irrespective of how long graduates have remained unemployed and their levels of education, the perceived level of stress are not significantly different.

The place of entrepreneurship education to assist under graduates and graduates to acquire relevant entrepreneurial skills that will make them self employed and have positive mental health was stressed as a way to reduce restiveness in our nation and the achievement of the 20:2020 visions.
\end{abstract}

\section{Introduction}

Universities are among other things, supposed to be the highest training grounds for the requisite human capital for national development. They are supposed to produce graduates, worthy in character and in learning who are to provide the intellectual as well as the skilled bases for societal progress and development. In the contemporary global order, in which skill acquisition and innovations are the engine of socio-economic growth and development, a country ignores the all round development of her youths only at her own developmental peril.

With increased globalization people seem to have seen the need to increase wealth creation especially within the developing nations such as ours. It has also become evident that neither the government nor the formal sector can supply the necessary job creation without the sustained effort and partnership between all sectors of the economy including the higher institutions.

The challenge posed by globalization requires that Nigeria mobilizes and harnesses the technical and entrepreneurial expertise of its, people to facilitate its own economic development. In view of this, the Federal government has come up with a vision that - "by 2020 Nigeria will be one of the 20 largest economies in the world, able to consolidate its leadership in Africa and establish itself as a significant player in the global economic and political arena". It seems to be quite obvious therefore, that Nigeria just cannot afford to stand still. The country simply has to move forward. Accordingly, a new way must be found to galvanize the entire populace especially the youths and unemployed graduates in order to transform the economy from its present peripheral, neo-colonial, dependent status to a modern, self-propelled and highly productive economy, ready to supply the needs of her people and properly situate the country within the global political economy.

A situation in which Nigerians as a people are languishing in the labyrinths of pauperization, ignorance and squalor in the mist of plenty should not be allowed to continue at this time and age.

Youth unemployment seems to be one of the major economic factors facing Nigeria. In the survey carried out by the World Bank [16], it was estimated that about 40 million Nigerians were unemployed. They also observed that one out of every five adults was employed, just as only one out of 10 university graduates was gainfully employed. In the latest report titled "Analyzing Employment and Growth For better Economic Policy" published in 2010, the World Bank Stated that "Notwithstanding strong growth in Nigeria's non - oil economy, unemployment did not fall between 1999 and 2006. On the contrary, youth unemployment markedly increased during the same period". 
Nigeria's growth performance seems not to have responded to the employment aspirations of its population as a whole, especially the younger generation. With the spate of factory closures which has worsened the youth unemployment situation in Nigeria, it cannot be overstated that other developing countries like Ghana, Indonesia and Malaysia have left Nigeria behind in terms of productivity, income generation and economic development. In a cargo economy where virtually everything is imported, the youth unemployment rate will continue to soar and social vices like: arm robbery, prostitution, substance abuse and kidnapping will be the order of the day.

Many researchers have shown that the adverse outcomes of globalization are not only economic but also psychological (Stokes [13], Ying [17]). Numerous authors contend that there are psychological consequences of unemployment in terms of adverse outcomes, both to the individual and to the family, which cannot be credited exclusively to economic deficiency (Schmidt [12], Winefield [15]). In particular, studies of the psychological impact of unemployment in school leavers have found that the unemployed show poorer psychological well-being on a range of measures than do the employed (Chase-Lansdale Mofitt, Lohman. et al. [4], Tiggermann \& Winefield [14]).

O’ Higgins (2001) concluded that the longer the unemployment period, the greater the cost to the person and to the society, in terms of physiological and psychological damage and negative effect on marriage and family. The majority of authors concurred that sustained unemployment imposes significant economic, personal and social costs that include: loss of current output, social exclusion, the loss of freedom, skill loss, psychological harm, ill health and reduced life expectancy, loss of motivation, the undermining of human relations and family life, loss of social value and responsibility. (Anderson [2]; Larsen [7]).

Moreover, when Tiggemann and Winefield [14] examined the effects of unemployment on the mood, self-esteem, locus of control and depressive affect of 761 Australian school-leavers they found that the unemployed were generally less well-adjusted than their employed counterparts. More specifically, all unemployed participants reported greater negative mood and had higher depression scores, while the unemployed female school-leavers also displayed lower self-esteem.

In Nigeria, there seems to have been very little organized institutional attention paid to unemployment. There has been no retraining programme for employees that have been laid off, and severance pay, relocation allowances and other extended benefits have always been withheld. At the National Policy level in Nigeria, discussions on strategies to increase the number of employment as a whole seem to have lacked implementations. Instead, the current monetization, increased use of technology, alterations of labour laws and reforms and international trade barriers have rendered more people jobless unabatedly.

The enormous unemployed youth in the Nigeria labour market may not only have been caused by the expansion of the educational system but also by lack of effective and good governance. Today, Nigeria has about 97 universities, which produce manpower for the labour market. There seems also to be a misconception between the social motive of government in increasing the population's access to education and the perception of the population that, their educational qualifications can only be used to secure white-collar jobs. On the part of the government, political office holders seem to have neither been planning for youth employment nor been answerable for government behaviours. They seem not have been responsive to the people from which their authority is derived.

\section{Statement of the Problem}

The employment difficulties facing graduates in Nigeria have negative consequences not just for the affected young people but for society as a whole. Persistent youth unemployment wastes human resources that could contribute to economic progress in the short-run, widespread unhappiness (of which rising suicide rates are a symptom) and social discontent among the youth, and may leave longterm scares on the working adults of the next generation. In extreme cases, alienated youth, especially if they are many, can cause social disruption in society, as in the case of Sierra Leon, Liberia and other war-torn countries.

Cursory observations reveal that, in Nigeria apart from the National Directorate of Employment (NDE) offices, which are located only in big cities, there are no career/employment offices where applicants can register their names and areas of specialization in order to secure employment after graduation. The government seems not to have provided the citizens with an acceptable level of public services in this area. This has led to flocks of youths who roam about the streets looking for means of keeping body and soul together.

According to Agbekodon [1] the need to avert the negative effects of unemployment should have tackling of unemployment problems featured very promptly in developing countries like ours.

\section{Purpose of the Study}

The purpose of this research work is to contribute to knowledge and provide empirical evidence on the state of mental health of Nigerian unemployed graduates. It also aimed to provide a possible way to 
better mental health through entrepreneurship education for self employment to achieve the nation’s vision 20:2020.

\section{Hypotheses}

Five hypotheses were generated to guide the study. The hypotheses were tested at 0.05 level of significance.

Ho1: The perceived level of stress among unemployed Nigerian graduates will not be significant.

Ho2: The employment status of Nigerian graduates will have no significant relationship with their stress somatic symptomatology.

Ho3: Sex of unemployed graduates will have no significant relationship with their stress somatic symptomatology.

Ho4: Academic qualification of unemployed graduates will have no significant relationship with their stress somatic symptomatology.

Ho5: The length of time graduates have stayed unemployed will have no relationship with their stress somatic symptomatology.

\section{Method}

\subsection{Participants}

167 subjects participated in this explorative research. All participants were volunteers living in Major cities in Nigeria who visited the National Directorate of Employment offices in search of jobs. They described their current job status as either unemployed ( $\mathrm{N}=147)$ or underemployed $(\mathrm{N}=20)$.

The participants comprised of male and female graduates from Nigeria higher educational institutions. The participants' ages ranged from 20 35 years. Participants were mostly single.

\subsection{Instruments}

5.2.1.Demographic Questionnaire. Subject were asked questions regarding their age, gender, marital status, work status, level of education and how long they have been unemployed.

5.2.2.The Self Report Questionnaire. A self report questionnaire (SRQ) was used to obtain information from respondents in this study. The self report Questionnaire (SRQ) is a collection of three self report dimensions intended to compute harmful emotional states of depression, anxiety and stress.
Items measures symptomatology such as hopelessness and devaluation of life. The anxiety scale (14 items) measures symptomalogy such as situational anxiety, skeletal muscle effect and autonomic arousal while the stress scale (14 items) measures symptomatology such as difficulty in relaxing, nervous arousal, being easily upset, irritated and impatient. The items in this questionnaire were adapted from the depression, anxiety stress scale of Lovibond and Lovibond [8], Goldberg's [5] version of General Health Questionnaire and Holmes \& Rahe [6] stress scale. Mumford, Minihas, Akhata \& Mubbashar [9] concurred to the use of questionnaire consisting of psychological sympotomatology as helpful in ascertaining psychological problems. There was no clinical diagnosis made by the researcher. All items in the questionnaire focused on cognitive symptoms and mood states. Participants were requested to indicate how true the items on depression and anxiety relate to them i.e Almost always true, often true, seldom true and almost never true. The responses were scored: Almost always true $=4$, often true $=3$, seldom true $=2$ and almost never true $=1$.

On the stress scale, respondents were to shade the appropriate degree of intensity of their experiences of the complaints. They were to shade either No complain, slight complain, moderate complain, severe complain. The responses were scored: No complain $=0$, slight complain $=1$, mild complain $=2$ moderate complain $=3$, severe complain $=4$ and very severe complain $=5$. The responses were analysed using standard deviation, means and t-test.

5.2.3. Validity and Reliability Of Instrument.The Self report questionnaire (SQR) for this study was given experts in clinical and counseling psychology who made useful suggestions. Based on their suggestions, some of the items were removed while some were reconstructed. The final copy of the items was agreed to have construct validity.

The reliability of the instrument was carried out using the test - retest method. The instrument was administered on 40 subjects in the population but outside the sample. After about 2 weeks, the instrument was again re- administered on the same set of subjects. The scores obtained in the two sets of administration was correlated using Person Product Moment Correlation test. A correlation coefficient of 0.75 was obtained for the instrument while the subsectional reliability coefficient of $0.72,0.75, .79$ were obtained for depression, anxiety and stress respectively.

\subsection{Procedure}

The researcher personally distributed the questionnaire to the various National Directorate of Employment (NDE). The self report questionnaire 
was administered by the research assistants engaged by the researcher in the NDE offices as they come to register as job seekers. Full written approval was given by the director of NDE where subjects were sampled.

\section{Results and Discussion}

The results of the research are presented in table 1 (see Appendix). The findings revealed that the calculated t-value of 2.620, exceeded the table value 1.96 at 0.05 level of significance. It also shows that the calculated mean of 65.8 is significantly higher than the theoretical mean of 62 .

Therefore the null hypothesis which states that the perceived level of stress among unemployed Nigerian graduates will not be significant is not accepted. The situation here is a flock of youth moving around under stress.

The table showed that males perceive more stress than the females (mean $=42.53$ and 39.50 respectively). In the same vein, the unemployed perceived more stress than the few under-employed who filled the questionnaires: $\mathrm{m}=45.62$ for unemployed and $\mathrm{m}=40.14$ for underemployed. The results also showed that irrespective of academic qualification the stress mean scores for the unemployed graduates were slightly high: ph.D/Masters = 40.33, BA/HND =42.29, NCE/Equivalent 41.04. It was also observed that irrespective of the years of being unemployed, the stress mean scores for all categories of unemployed graduates were also slightly high i.e. $0-2$ years = 39.92, $3-5$ years $=43.74,6-8$ years $=37.14$ and 9 years - above $=40.58$.

Patton and Noller (2009) observed that leaving school and engaging in a job was associated with increased positive mental health and psychological well-being whereas leaving school and becoming jobless was associated with depression, crime oriented behaviours and general deterioration of mental health.

It therefore becomes imperative for Nigeria higher education institutions to build well functional entrepreneurship education into their curriculum so that their products can become gainfully self employed after graduation.

\section{Concept of Entrepreneurship}

Entrepreneurship refers to an individual's ability to turn ideas into action. It includes creativity, innovation and risk taking as well as the ability to plan and manage project in order to achieve objectives. Entrepreneurship education is aimed at promoting creativity, innovations and selfemployment and may include the following elements:
- Developing personal attributes and skills that form the basis of an entrepreneurial mindset and behaviour (creativity, sense of initiatives, risk taking, autonomy, self confidence, leadership and team spirit)

- Raising the awareness of students about selfemployment and entrepreneurship as possible options;

- Working on concrete enterprise projects and activities.

- Providing specific business skills and knowledge of how to start a company and run it successfully.

Entrepreneurship education offer students the tools to think creativity, be an effective problem solver, analyze a business idea objectively, and communicate, network, lead and evaluate any given project. It also helps students to feel more confident about setting up their own business.

Entrepreneurial mindsets, knowledge and abilities will be of benefit to young people in all walks of life.

Historically, entrepreneurship has been associated with small business and viewed as a less attractive career option for dynamic university graduates. A shift in attitudes among students can be fostered by introducing and promoting the dynamic innovative and ambitious face of entrepreneurship.

\section{Entrepreneurship in Nigeria Higher Institutions}

The important role of higher education institutions in promoting entrepreneurial attitudes and behaviours seems to be now widely recognized. In its practical approach to redress the seemingly unrealistic educational curricula of the university educational system to solve the economic problems in Nigeria, the Federal Government feels the need to promote the collaborative efforts of all asundry in Nigeria universities. Realizing the important role of the higher educational system as an instrument of creating wealth, business opportunities, economic development and global market competitiveness, the Federal Government through the National University Commission (NUC), directed all higher institutions to include entrepreneurship in the curricular. NUC is the major accreditation body that enforces uniform standard and sets admissions capacity for every university in the country.

Cursory observations revealed that a great number of the universities have not complied with this directive and those that have complied do not really train the students as they ought to do but engage in occasional practical sessional programmes for the undergraduates.

Integration of entrepreneurship into the curricula needs to be the vision for all higher education 
institutions as part of their wider mission. Provision should be accessible for Arts and Humanities students as it is for Business/Social Science and Science/Engineering students.

A range of courses, rather than settling on a particular model of delivery should be offered. In the early stages of promoting entrepreneurship education, it may be better to have a diverse range of provision: options that students can take extracurricular activities, business plan competitions and other activities that have added advantage of bringing the local business community into the educational environment. New undergraduates may be encouraged to seek greater entrepreneurship awareness/understanding ideas, opportunities, motivation, confidence to act and new social networks and the 'near' graduate and post graduate may be encouraged to exploit opportunities for entrepreneurship. Therefore, within a variety of courses that higher education institution can offer, including some inter-disciplinary ones, such aspects as: generating ideas and recognizing opportunities, creating new ventures/organizations and growing young ventures should be covered. Other areas such as: innovation management, corporate entrepreneurship and entrepreneurship; entrepreneurial management; entrepreneurial marketing and finance, and corporate successions may be included.

\section{Delivering Entrepreneurship Education}

In delivering entrepreneurship education, the purpose of the course/ programme should be precisely defined being linked to the delivery of the expected outcome to indicate a balance between theoretical and practical aspects. It is advisable that teaching should make use of interactive and pragmatic methods; active self-learning, actionoriented pedagogy, group work, learning through projects, student centered methods, learning by direct experience; methods of self development and selfassessment. Moreover, delivery should be through mechanisms that maintain the motivation of students at high level.

There should be a collaborative approach with real business practice and industry. Therefore, a close relationship should be in place with the local entrepreneurial environment and educators as part of relevant network. The importance of young entrepreneurs should not be overlooked (for instance, alumni who have started a company) and experienced business people contributes to the learning design. Practical experience with enterprises and working on concrete enterprise project should be embedded in the programme. Exchange of ideas and experiences between teachers and students from different universities should be sought and promoted to encourage mutual learning and to give an interuniversity perspective to programmes, courses and activities.

\section{Challenges of Entrepreneurship Education}

A basic principle is that Entrepreneurship education should spread horizontally in the curriculum, across different fields of study. In this respect one major challenge is the division of higher education institution into different faculties and schools.

This may work against the kind of cross-cutting that favours multidisciplinary teams and projects. Faculties and departments are very often working quite separately, with many obstacles for students who want to move and for teachers interested in establishing cross-disciplinary courses. This curriculum structure can often be an impediment.

The current funding in Nigerian higher institutions of learning is in clear mismatch to the demand for entrepreneurship studies. With the current inadequate funding, adding the financial burden of entrepreneurship education successfully may be difficult if not impossible.

There are currently few lecturers and professors of entrepreneurship in Nigeria and many of them have not been trained from the start in the field. As a consequence they may be unaware of the right approach to entrepreneurship teaching.

It is hoped that subsequent policy makers in Nigeria will uphold this vision of entrepreneurship education otherwise changing political office holders, with their changing priorities and orientation could pose a major challenge. This could be worsened by the bureaucratic culture inside the institutions and organizational inertia, inappropriate institutional polices practices, cultures and structures. In the few universities where entrepreneurship education is taught there are no established systems for evaluating the programmes' results. Courses are taught just as academic courses by educators who have no link with business life. Moreover, there is this lack of desire to change the way in which teaching has always been delivered through the lecture method.

\section{Recommendation and Conclusion}

In order to improve the mental health of Nigerian graduates and achieve the 20:2020 vision, Nigeria needs to stimulate the entrepreneurial mindsets of young people, encourage innovative business startups and foster a culture that is friendlier to entrepreneurship and to the growth of small and medium size enterprises (SMES). 
Currently, the teaching of entrepreneurship is not yet sufficiently integrated in all Nigerian higher education institutions curricula. This should be integrated with all urgency and the National University Commission (NUC) should accredit and validate this department like all other university courses.

The purpose of the course/programme should be precisely defined, as should its expected outcome(s). While the creation of graduate start-ups is therefore a desirable outcome, it should not be forgotten that entrepreneurship is also (and equally) about successfully managing innovation and growth. In existing business and entrepreneurship programmes very often only the start-up aspect is considered, while the skills and knowledge needed to manage the growth phase of a small business are neglected. In this sense, there is in general terms a need for a shift in the focus of entrepreneurship education programmes and courses across all Nigeria universities to embrace all aspects of the programme. A perceived lack of relevant experience and a lack of self-confidence are two often cited reasons for new graduates not engaging in entrepreneurship soon after graduation. The university experience should be capable of addressing both these needs.

The learning experience needs to build depth and breadth in awareness, understanding and capacity. Although not applicable in all cases, the general approach would be to provide broad exposure and positive and motivational experiences during the early stages of university life. This then provides a platform from which to build depth and capability in preparation for an entrepreneurial career at the point of exit. The important point here is one of progression, not only through university, but also through the whole education system at all levels.

The strength that gives higher education institutions an innovative capacity, and hence entrepreneurial potentials, is their autonomy. Given the right framework conditions, entrepreneurial initiatives can be highly desirable for an institution, as successful initiatives lend the prestige to the institution. They can also help bridge the funding gap that is chronically facing most higher education institutions in Nigeria. While diversity is richness, higher education institutions and educators will benefit from exchanges and mutual learning, open sources of information, and examples of good practice across all institutions. Coordination should be applied at a policy level to ensure that all higher education institutions are given the necessary incentives and opportunities to take on this challenge.

Entrepreneurial teaching should be highly valued in all institution, within the curricula of the different faculties, with reward mechanisms in place, qualified educators and a wealth of inter-actions with the outside world, in particular with business and entrepreneurs. In this respect, the development and delivery of entrepreneurship is significantly affected by the internal organizational structure of the institution. Irrespective of the individual objectives of a university or college, having more effective internal organization structures is recommended.

In conclusion, graduate unemployment seem to have risen because the Nigerian economy is not expanding at a rate commensurate with the output of university graduates. Graduate unemployment therefore should be recognized as a major socioeconomic challenge by all stakeholders. The introduction of Enterprises Education (EE) into educational system should include all levels of education. To achieve sound entrepreneurship training, there must be a combination of classroom expertise and skill acquisition practice. Beyond introduction of entrepreneurship into university curriculum, attention should be directed to both vocational and entrepreneurial skills as complements rather than substitutes. It is expected that Nigeria institutions of higher learning will take their rightful place in midwifing production of graduate entrepreneurs with good mental health who are capable of driving the nation's economy in achieving one of her great goals; to become one of the World's 20 leading economies by the year 2020 .

\section{References}

[1] Agbekodon, A.B., (2009). Reviewing Employment status in Nigeria. Ibadan: Ebireni publishers.

[2] Anderson, J.G., (2002). Coping with long-term unemployment: Economic Security, Labour market integration and well-being. Results from Danish study, 1994-1999. International journal of social welfare, 11(3), 178-190.

[3] Butterworth, A.P, Rodger B.M., (2006). Infering the meaning of work from the effects ofunemployment. Journal of Applied psychology 33, 1045-1054.

[4] Chase-Lansdale, P.L, Mofitt, R.A, Lohman B.L., (2003). How are children affected by employment and welfare transitions? http://www.jcpr.org/ policybriefs/vol5 num3.htm.

[5] Goldberg, D.P., (1979). A user's Guide to the General Health Questionnaire, NFER Nelson, Windsor.

[6] Holmes, T.H \& Rahe, M., (1994). The social readjustment rating scale. Journal of Psychosomatic research 11, 213-218.

[7] Larsen, C.A., (2003). Structural unemployment. An analysis of recruitment and selection mechanism based on panel data among Danish long-term unemployment. International journal of social welfare, 12(3), 170-181. 
[8] Lovibond, S.H \& Lovibond, P.F., (1995). Manual for the Depression Anxiety Stress Scales (2nd ed). Sydney: Psychological Foundation.

[9] Mumford, D.B, Minhas, F.A, Akhat, I. and Mubbashar M.H., (2000). Stress and Psychiatric disorder in urban Rawalpindi : Community survey. British journal of Psychiatry, 177,557-5562.

[10] O’ Higgins, N., (2001). Youth Unemployment and Employment policy: A global perspective. Geneva : International Labour Organisation.

[11] Patton, W. \& Noller, P., (2009). Unemployment and youth : A longitudinal study. Austrialian Journal of Psychology, 36(3), 399-413.

[12] Schmidts, D., (2006). Globalization at work. Finance and Development, 43,

www.imf.org/external/pubs/ft/fandd/2006/03/picture.htm.

[13] Stokes, B., (2006). Denmark invests in an adaptable workforce, thus reducing fear of change. http://yaleglobal.yale.edu.display.

[14] Tiggerman, M., Winefield, A.H., (1992). A longitudinal study of the psychological effects of unemployment and unsatisfactory employment in Young adults. Journal of applied psychology, 76, 424-431.

[15] Winefiefld, A. H., (1996). The effects of unemployment on the mood, self-esteem, locus of control and depressive affect of school-leavers. Journal of occupational Psychology, 57, 33-42.

[16] World bank, (2009). African Development indicators 2006/2007, The World Bank Washington D.C.

[17] Ying, H.Y., (2006). Globalization: Beat unemployment and jobs out sourcing. www.globalcareerinformation.com/articlegob/.htm 